Document downloaded from:

http://hdl.handle.net/10251/79099

This paper must be cited as:

Jornet Olivé, MD.; Castillo López, MÁ.; Sabater Marco, C.; R. Domingo, L.; Tormos Faus, RE.; Miranda Alonso, MÁ. (2013). Xanthone-photosensitized detoxification of the veterinary anthelminticfenbendazole. Journal of Photochemistry and Photobiology A: Chemistry. 264:34-40. doi:10.1016/j.jphotochem.2013.05.002.

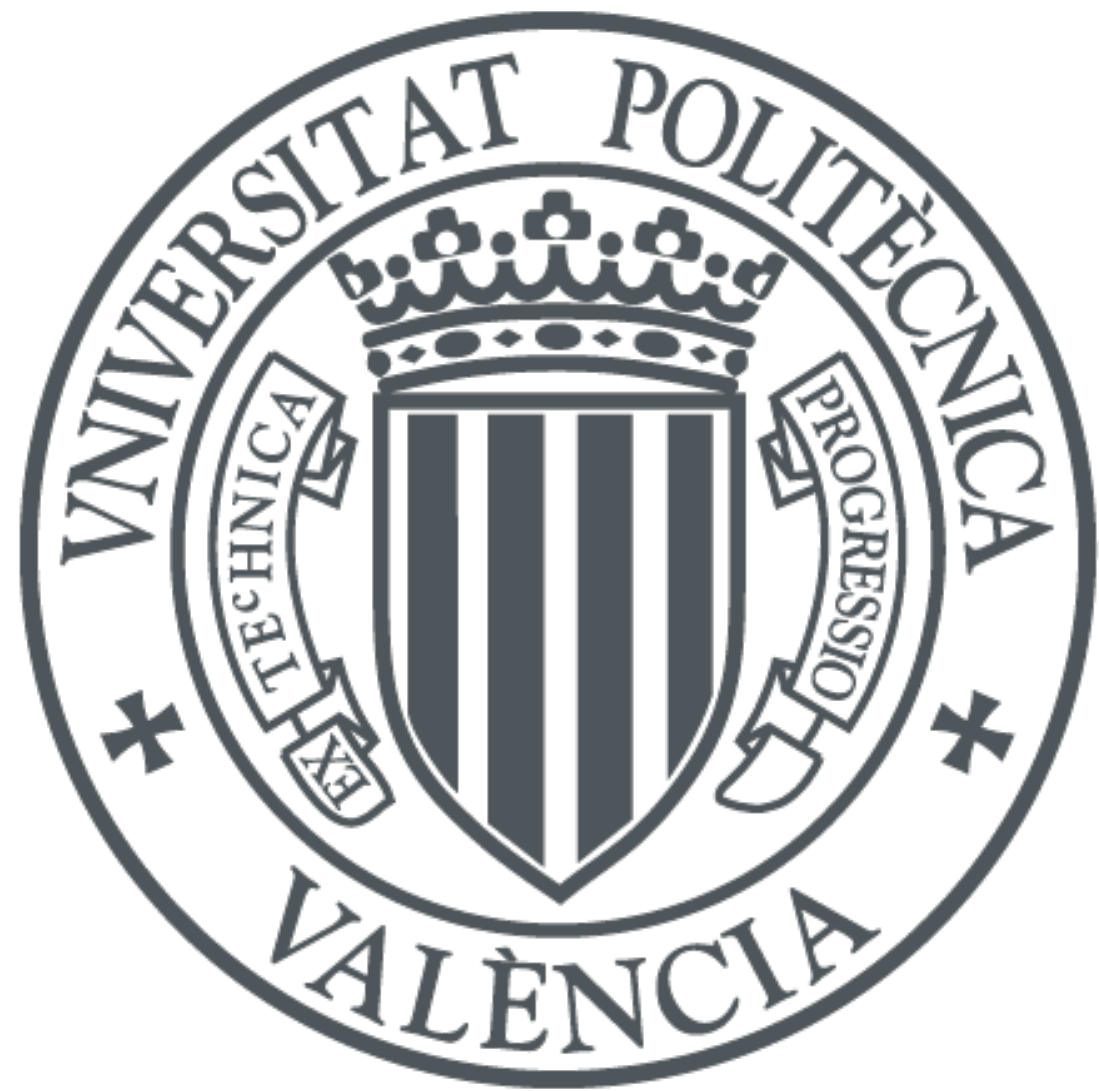

The final publication is available at

http://dx.doi.org/10.1016/j.jphotochem.2013.05.002

Copyright Elsevier

Additional Information 


\title{
Xanthone-photosensitized detoxification of the veterinary anthelmintic fenbendazole
}

\author{
Dolors Jornet ${ }^{\mathrm{a}}, \mathrm{M}^{a}-$ Angeles Castillo ${ }^{\mathrm{b}}, \mathrm{M}^{a}{ }^{a}$ - Consuelo Sabater ${ }^{\mathrm{b}}$, Luis R. Domingo ${ }^{\mathrm{c}}$, \\ Rosa Tormos $^{\mathrm{a}, *}$, Miguel A. Miranda ${ }^{\mathrm{a}, *}$
}

\begin{abstract}
Fenbendazole $(\mathbf{1})$ is a common veterinary anthelmintic, toxic to water living microorganisms. Fluorescence quantum yields of $\mathbf{1}$ were found to be 0.11 in acetonitrile, 0.068 in methanol, 0.034 in cyclohexane, and 0.013 in water. The singlet excited state energy was $c a .96 \mathrm{kcal} \mathrm{mol}^{-1}$ in all solvents. The phosphorescence spectrum of $\mathbf{1}$ in ethanol at $77 \mathrm{~K}$ displayed a maximum at $450 \mathrm{~nm}$, leading to a triplet energy of $75 \mathrm{kcal} \mathrm{mol}^{-1}$. Experimental excited state energies agree well with the results of DFT calculations at the time-dependent B3LYP / 6-311+G(d,p)/ / B3LYP/6-31G(d) level. Laser flash photolysis (LFP) of $\mathbf{1}$ at $266 \mathrm{~nm}$ led to transients absorbing in the $300-700 \mathrm{~nm}$ range, ascribed to radical cation $\mathbf{1}^{+}$, which were also observed upon $355 \mathrm{~nm}$ LFP of xanthone (XA) in the presence of $\mathbf{1}$. Solar-simulated photolysis revealed XA-enhanced photodegradation of $\mathbf{1}$ and led to decreased toxicity, as shown by Daphnia magna assays.
\end{abstract}

\section{Introduction}

Compounds containing the benzimidazole (BZ) moiety have found application as anthelmintic and are effective as antinematodal and anti-protozoal agents [1,2]. More interestingly, in the course of investigations on the development of anthelmintic resistance to $\mathrm{BZs}$ it has been discovered that they bind specifically and with high affinity to 13-tubulin (13-TUB) monomer before dimerization with cx-TUB and subsequent blockade of microtubule formation [3,4]; this effect has been exploited for inhibition of cancer cell proliferation by suppressing microtubule dynamics [5]. In this context, thestudy of TUB-BZ interactions has been a very active area of research, in view of its biological importance.

Unfortunately, many BZs are toxic to humans and animals, so recent studies have focused not only on the elimination of these xenobiotics from the environment, but also on their ecological hazard [6]. Moreover, the extensive use of BZs may leave residues in edible tissues or in animal-derived food, such as milk, egg and meat [7].

Sunlight exposure contributes to the degradation of pesticides and can in principle be used as a tool for environmental remediation. However, little attention has been devoted to the effects of light on BZs. Photochemical studies are limited to the parent molecule and some of its derivatives $[8,9]$, and only recently few studies have appeared on their photo-elimination from the environment [10-12].

Specifically, methyl [5-(phenylthio)-1H-benzimidazol-2yl]carbamate (fenbendazole, 1) known commercially as Panacur (Chart 1), is a veterinary biocide extensively used against gastrointestinal parasites in farm animals and pets [13].

Recently the synergistic effect of $\mathbf{1}$ with an anti-oxidant on the growth of human cancer cells has been reported [14], but in parallel its toxicity to the water living microorganisms has also been proved [6]. By contrast with the widespread utilization of $\mathbf{1}$, its photobehavior remains relatively unknown. In this field, the studies on $\mathbf{1}$ are limited to the degradation process in methanolic solution under simulated sunlight, which leads to formation of two hydrolysis products [15]. However, the involved singlet and/or triplet excited states and other possible transients have not been investigated as yet. With this background, the aim of the present work is the full characterization of photophysical properties of fenbendazole. This knowledge is an essential requirement to check, in a later stage, the possibility of using $\mathbf{1}$ as a probe for host-guest interaction, such as complexation with cyclodextrin or with tubulin, through fluorescence and/or triplet excited state changes. In addition, recent work has demonstrated the relatively high toxicity of $\mathbf{1}$ compared with other members of the BZ family [6]; in this context, we wish now 



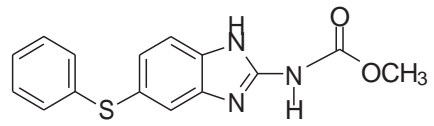

Chart 1. Fenbendazole molecular structure.

to explore the feasibility of using light for detoxification of water polluted with $\mathbf{1}$, wich has been evaluated by an established model based on the inhibition of mobility of Daphnia magna.

\section{Experimental}

\subsection{Materials and solvents}

Fenbendazole (1), xanthone (XA), S-flurbiprofen, thiabendazole and tert-butyl peroxide were purchased from Aldrich. Their purity was checked by ${ }^{1} \mathrm{H}$ nuclear magnetic resonance (NMR) spectroscopy and high performance liquid chromatography (HPLC) analysis. Reagent grade solvent acetonitrile and methanol were purchased from Scharlau and used without further purification. The water was Millipore quality.

\subsection{Absorption and emission spectra}

Optical spectra in different solvents were measured on a Jasco V-630 spectrophotometer. Emission spectra were recorded on a spectrofluorometer system Jasco FP-8500, provided with an M 300 emission monochromator in the wavelength range of $200-900 \mathrm{~nm}$ and are uncorrected. Samples were placed into $10 \mathrm{~mm} \times 10 \mathrm{~mm}$ Suprasil quartz cells with a septum cap. Solutions were purged with nitrogen or oxygen for at least $10 \mathrm{~min}$ before the measurements. Fluorescence quantum yields were determined using $S$-flurbiprofen as reference $\left({ }_{\mathrm{F}}^{\circ}=0.27\right.$ at $>_{\operatorname{exc}}=281 \mathrm{~nm}$ in methanol as solvent) [16]. The absorbance of the samples at the excitation wavelength was kept below 0.1. Excitation and emission slits were maintained unchanged during the emission experiments. Fluorescence lifetime measurements were based on a PTI(TM-2/2003) instrumentequipped with $\mathrm{H}_{2} / \mathrm{N}_{2} \operatorname{lamp}(50 / 50,1.5$ ns pulsewidth) and a stroboscopic detector. All experiments were performed at room temperature $\left(22^{\circ} \mathrm{C}\right)$.

\subsection{Laser flash photolysis experiments}

The LFP experiments were carried out by using a Q-switched Nd:YAG laser (Quantel Brilliant, 266 or $355 \mathrm{~nm}, 10$ or $14 \mathrm{~mJ}$ per pulse, $5 \mathrm{~ns}$ fwhm) coupled to a mLFP-111 Luzchem miniaturized equipment. This transient absorption spectrometer includes a ceramic xenon light source, $125 \mathrm{~mm}$ monochromator, Tektronix 9-bit digitizer TDS-3000 series with $300 \mathrm{MHz}$ bandwith, compact photomultiplier and power supply, cell holder and fiber optic connectors, fiber optic sensor for laser-sensing pretrigger signal, computer interfaces and a software package developed in the LabVIEW environment from National Instruments. The LFP equipment supplies $5 \mathrm{~V}$ trigger pulses with programmable frequency and delay. The risetime of the detector/digitizer is approximately $3 \mathrm{~ns}$ up to $300 \mathrm{MHz}$ (2.5 GHz sampling). The laser pulse is probed by a system containing a fiber that synchronizes the LFP with the digitizer operating in the pretrigger mode. All transient spectra were recorded using $10 \mathrm{~mm} \times 10 \mathrm{~mm}$ quartz cells with $4 \mathrm{~mL}$ capacity, and all were bubbled during 20 min with $\mathrm{N}_{2}$. Absorbance of the samples was kept between 0.2 and 0.3 at the laser wavelength. All the experiments were carried out at room temperature.

\subsection{Computationalmethods}

Density functional theory (DFT) calculations were carried out using the B3LYP $[17,18]$ exchange correlation functional, together with the 6-31G(d) and 6-311+G(d,p) basis sets [19]. Optimizations were carried out using the Berny analytical gradient optimization method [20,21]. Electronic structures of stationary points were analyzed using the Wiberg indices [22,23]. Vertical energies of the singlet and triplet excited states were calculated using the timedependent (TD-DFT) method [24,25]. Solvent effects of acetonitrile on the excited states were considered by TD-DFT calculation on the gas-phase structures using a self-consistent reaction field (SCRF) $[26,27]$ based on the polarizable continuum model (PCM) of the Tomasi's group [28-30]. All calculations were carried out with the Gaussian 03 suite of programs [31].

\subsection{Irradiation procedure}

Aerated solutions of $\mathbf{1}$ in DMSO $\left(5.2 \times 10^{-4} \mathrm{M}\right)$ were submitted to irradiation in the absence and in the presence of $\mathbf{X A}\left(5.2 \times 10^{-4} \mathrm{M}\right)$ using a solar simulator (ABET Technologies Sun 2000). The course of the photoreaction was monitored by means of analytical HPLC, using reverse phase C18 column and methanol-water (50:50, v/v) with $0.6 \%$ of ammonia as eluent. The flow rate was $0.8 \mathrm{~mL} / \mathrm{min}$, and the detector was a photo diode array (PDA).

\subsection{Toxicityassays}

The ephippia (dormant eggs) of crustacean D. magna were supplied by ECOtest S.L. (Valencia, Spain). The toxicity assays were performed assessing the inhibition of the mobility of D. magna according to the standard ISO 6341:1996 [32] procedure. The bioassay uses $24 \mathrm{~h}$ old daphnids hatched from the ephippia. Five neonates were placed in $15 \mathrm{~mL}$ appropriate containers with $10 \mathrm{~mL}$ of test dilution. The assays were conducted in the dark at a constant temperature of $21 \pm 1^{\circ} \mathrm{C}$. At the end of the test period (70h) mobile D. magna were counted in each container. Those unable to swim in the $15 \mathrm{~s}$ after agitation were considered immobile. All experiments were done in quadruplicate.

Different dilutions were prepared with thestandard freshwater, according to mentioned guideline. Standard freshwater was also used as hatching medium.

Assays were conducted with a range of test dilutions in geometric progression plus the controls. Whenever possible, data were used to calculate the $\mathrm{EC}_{50}$ (sample dilution required to immobilize $50 \%$ of the daphnids after $24 \mathrm{~h}$ exposure) by Probit analysis, using the Statistical Analysis System SPSS (version 16.0). Toxicity data were analyzed with one-way analysis of variance (ANOVA) to inspect the effect of treatment time $(70 \mathrm{~h})$. The Fisher's least significant difference (LSD) test was used to determine which treatments are statistically significant with respect to the untreated sample. A $P<0.05$ was taken to indicate statistical significance (STATGRAPHICS PLUS version 5.1).

\section{Results and discussion}

\subsection{Photophysical properties in solution}

In a first stage, the absorption properties of fenbendazole (1, Chart 1) were studied in different solvents. As shown in Fig. 1, the spectra in $\mathrm{MeCN}$ and $\mathrm{MeOH}$ are superimposable and display three bands with maxima at 220, 250 and $295 \mathrm{~nm}$. In aqueous solution the long-wavelength band is shifted to the red $17 \mathrm{~nm}$. In acidified water the maxima appear at 230 and $295 \mathrm{~nm}$, whereas in cyclohexane the lowestenergy maximum is located at $280 \mathrm{~nm}$. The observed solvent 


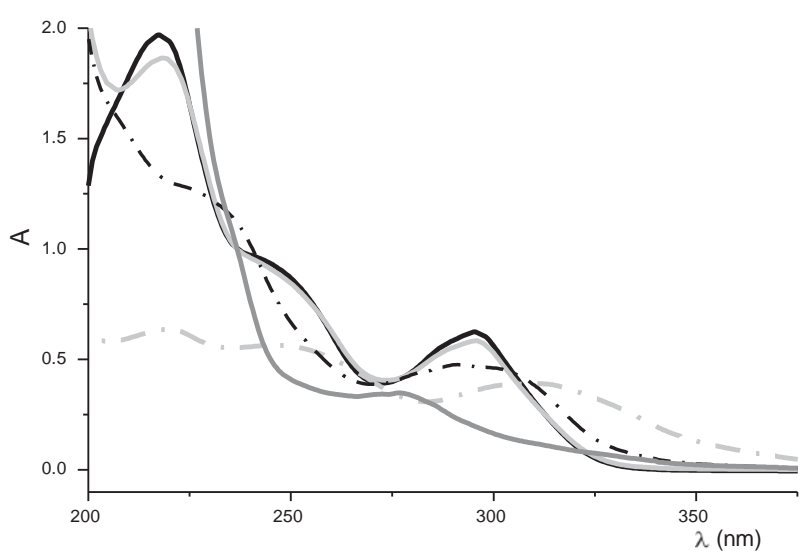

Fig. 1. Absorption spectra $\left(4 \times 10^{-5} \mathrm{M}\right)$ solutions of $\mathbf{1}$ in $\mathrm{MeOH}(-), \mathrm{MeCN}(-), \mathrm{H}_{2} \mathrm{O}$ pH: 7,5(-·-), $\mathrm{H}_{2} \mathrm{O}$ pH: $1(-\cdot-)$ and $\mathrm{C}_{6} \mathrm{H}_{12}(-)$.

effects are in good agreement with the TITI* electronic configuration of the lowest singlet excited state.

Next, the emission spectra of $\mathbf{1}$ were recorded under different conditions, upon excitation at the long wavelength absorption band. It was clearly observed (Fig. 2) that the shape and position of the emission band in MeCN matches with that recorded in methanol and cyclohexane with the maximum at $330 \mathrm{~nm}$, while in water the maximum is shifted to $356 \mathrm{~nm}$.

The excitation spectrum for the emission at $330 \mathrm{~nm}$ in $\mathrm{MeCN}$ solution is also shown in Fig. 2. From the intersection between the two bands, after normalization, a singlet excited state energy of $96 \mathrm{kcal} \mathrm{mol}^{-1}$ was determined. A similar value was obtained in the other organic solvents. In water, the corresponding energy was found to be $87 \mathrm{kcal} \mathrm{mol}^{-1}$. Again, the dependence of the emission properties on the polarity of the solvent support the TITI* nature of the excited singlet state.

The fluorescence quantum yield was measured in all media, and the values were found to be 0.11 in acetonitrile, 0.068 in methanol, 0.034 in cyclohexane and 0.013 in water. The lifetime was found to be in all cases shorter than $1 \mathrm{~ns}$, the detection limit of the apparatus.

The phosphorescence spectrum of $\mathbf{1}$ in ethanol at $77 \mathrm{~K}$ consisted of an almost structureless emission with a maximum centered at $450 \mathrm{~nm}$ (Fig. 2). The triplet energy was determined as $75 \mathrm{kcal} \mathrm{mol}^{-1}$.

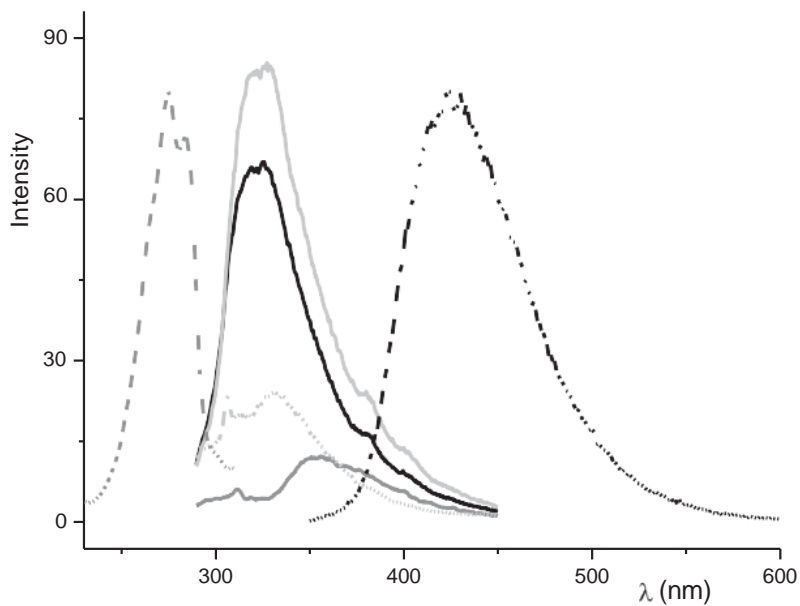

Fig. 2. Emission spectra of $\mathbf{1}$ in $\mathrm{MeCN}(-), \mathrm{MeOH}(-), \mathrm{C}_{6} \mathrm{H}_{12}(-)$ and water (-) upon excitation at $290 \mathrm{~nm}$, together with excitation spectrum $(-)$ in $\mathrm{MeCN}\left(>_{\mathrm{em}}=330 \mathrm{~nm}\right)$ and the phosphorescence spectrum (-) in ethanol at $77 \mathrm{~K}$.
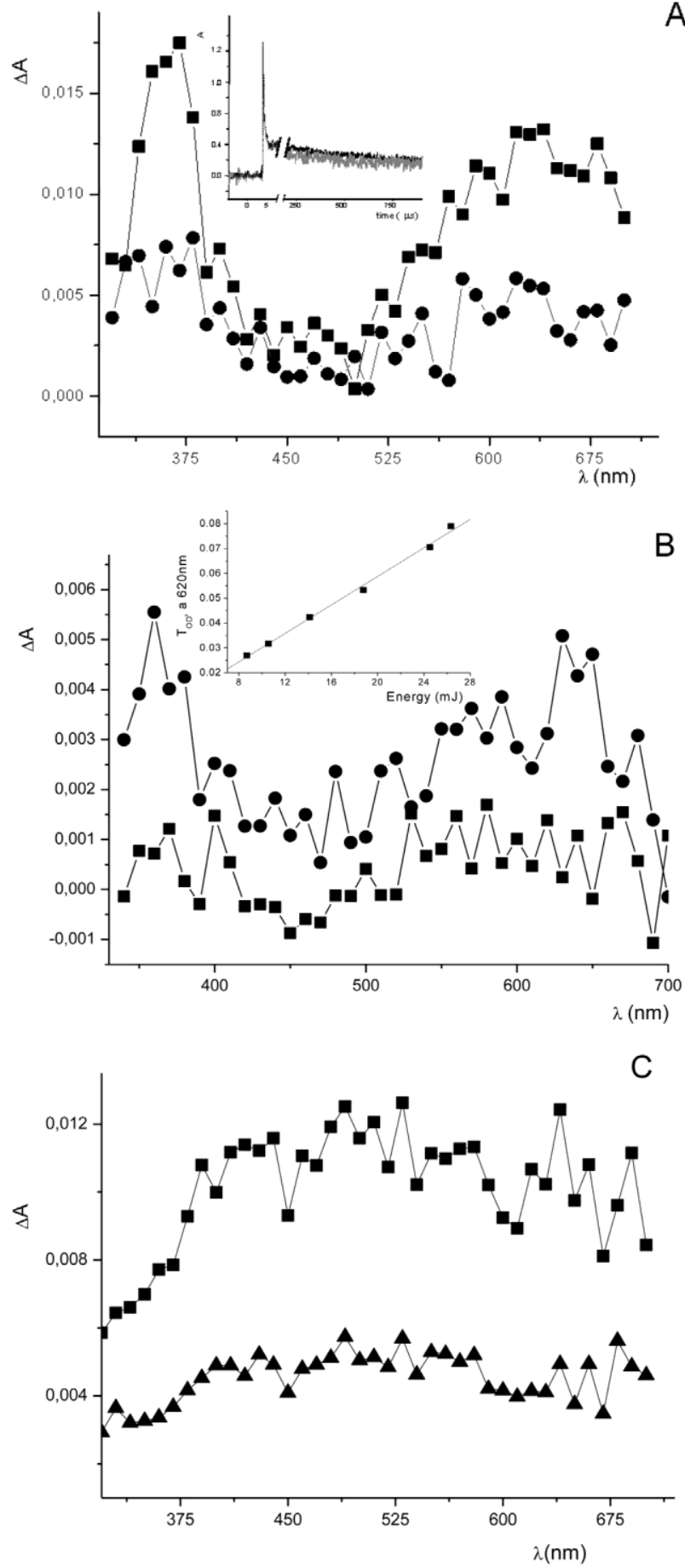

Fig. 3. (A) Transient absorption spectra of $\mathbf{1}\left(5.3 \times 10^{-4} \mathrm{M}\right)$ in acetonitrile after $266 \mathrm{~nm}$ irradiation $(10 \mathrm{~mJ})$ registered at $2 \mu \mathrm{s}(\cdot)$, and $120 \mu \mathrm{s}(\cdot)$ delay times. Inset: normalized decay traces at $365 \mathrm{~nm}$ (black) and $600 \mathrm{~nm}$ (gray). (B) Transient absorption spectra of $\mathbf{1}\left(2.8 \times 10^{-4} \mathrm{M}\right)$ in water after $266 \mathrm{~nm}$ irradiation $(10 \mathrm{~mJ})$, registered at $1 \mu \mathrm{s}(\bullet)$, and $100 \mu \mathrm{s}(\cdot)$ delay times. Inset: dependence of the initial transient absorbance at $620 \mathrm{~nm}$ on the energy of the laser pulse. (C) Transient absorption spectra of $\mathbf{1}\left(3.4 \times 10^{-4} \mathrm{M}\right)$ in cyclohexane after $266 \mathrm{~nm}$ irradiation $(10 \mathrm{~mJ})$, registered at $0.01 \mu \mathrm{s}(\cdot)$, and $0.06 \mu \mathrm{s}(\cdot)$ delay times.

\subsection{Transient absorption spectroscopy}

After examining the absorption and emission behavior, transientabsorptionspectroscopy studieswereundertaken. Thus, laser flash photolysis ( $>=266 \mathrm{~nm}$ ) of a deaerated solution of $\mathbf{1}$ in acetonitrile (Fig. 3A) or water (Fig. 3B) led to transients absorbing in the 


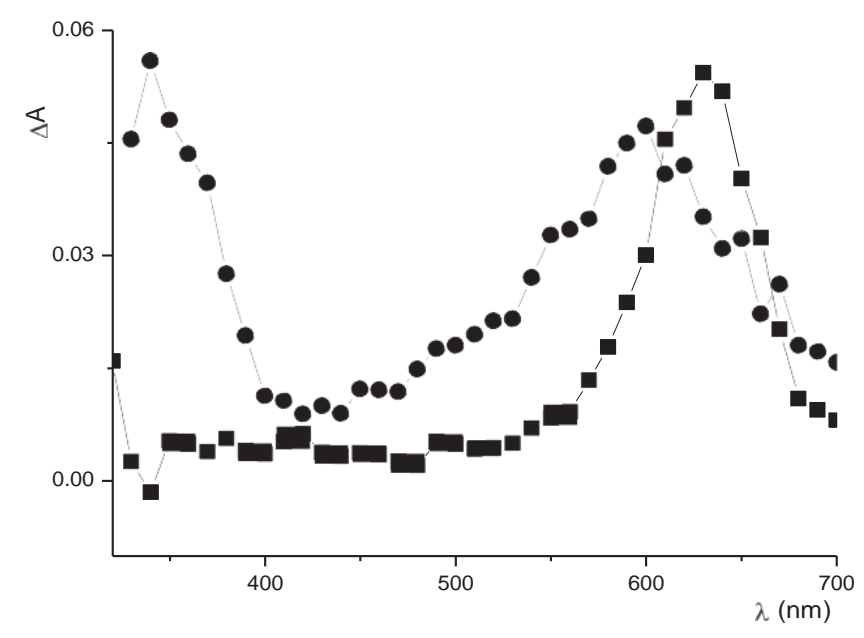

Fig. 4. Transient absorption spectra obtained after $355 \mathrm{~nm}$ LFP of acetonitrile solutions of XA alone $(\cdot)$ and in the presence of $\mathbf{1}(\cdot)(1: 5$ ratio), registered at $0.7 \mu \mathrm{s}$ after the laser pulse.

$300-700 \mathrm{~nm}$ range. The spectra obtained $2 \mu$ s after the laser pulses showed maxima at $c a .350$ and $600 \mathrm{~nm}$.

The decays in acetonitrile (Fig. 3A inset) were nearly coincident at the two wavelengths. They were satisfactorily fitted to a function containing two monoexponential terms. The shorter decay time was clearly in the submicrosecond timescale, whereas the longer one was found to be $175 \mu \mathrm{s}$. In principle these transient signals could be ascribed to a triplet, a radical cation or a neutral radical. For the assignment, LFP of aereated and deareated solutions of $\mathbf{1}$ in acetonitrile was performed, and no difference could be noticed in the long-lifetime component; thus the bands shown in Fig. 3A are not attributable to a triplet. In order to discriminate between a radical and a radical cation, an alternative approach to generate the former was followed. Hence, a solution of $\mathbf{1}$ in a mixture of acetonitrile and tertbutylperoxide $(10: 1, \mathrm{v} / \mathrm{v})$ was photolyzed at $355 \mathrm{~nm}$. Under these conditions the generated tert-butoxy radical ( $\mathrm{RO}^{*}$ ) should abstract hydrogen from 1, leading to formation of tert-butanol and a $\mathrm{N}$-centered radical [33]. No spectrum was obtained, suggesting that the transient is a radical cation, rather than a neutral radical.

Parallel experiments were performed in $\mathrm{H}_{2} \mathrm{O}$ and in cyclohexane as solvents (Fig. 3B and Crespectively). As expected for a radical cation, in aqueous medium the spectral bands were also found and the decay kinetics was monoexponential at the two maxima $(r=184 \mu \mathrm{s})$. A plot of the signal intensity vs. pulse energy is shown in the inset of Fig. 3B. Its linearity revealed that photoionization is a monophotonic process.

As regards the LFP experiment in cyclohexane, where photoionization is not expected, a flat transient spectrum was obtained in the region $375-700 \mathrm{~nm}$. Its lifetime was in the submicrosecond time domain $(c a .0 .1 \mu \mathrm{s})$. On the basis of oxygen quenching, this species was assigned to the triplet-triplet absorption of $\mathbf{1}$. This can explain observation of the short-lived component in acetonitrile.

Additional support in favor of radical cation formation in acetonitrile was obtained by $355 \mathrm{~nm}$ LPF of xanthone (XA) in the presence of $\mathbf{1}$, which led to a fast decay of the initially formed XA triplet signal at $630 \mathrm{~nm}$, concomitantly with the growth of two bands with maxima centered around $350 \mathrm{~nm}$ and $600 \mathrm{~nm}$ (Fig. 4). Thus, the formed species can be reasonably attributed to $\mathbf{1}^{++}$. The counter ion $\mathbf{X A} \mathbf{A}^{--}$is known to absorb in the same spectral region. So, it would give rise to significant overlap [34].

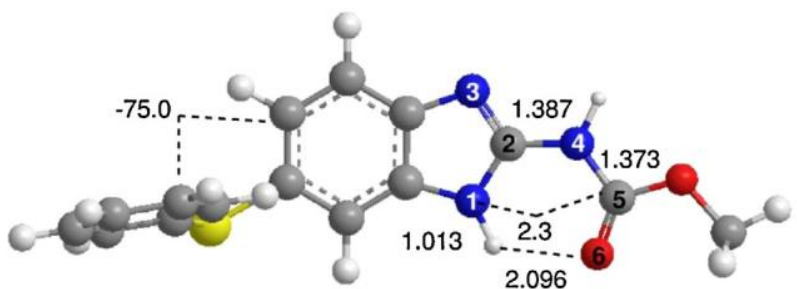

s-cis fenbendazole (1c)

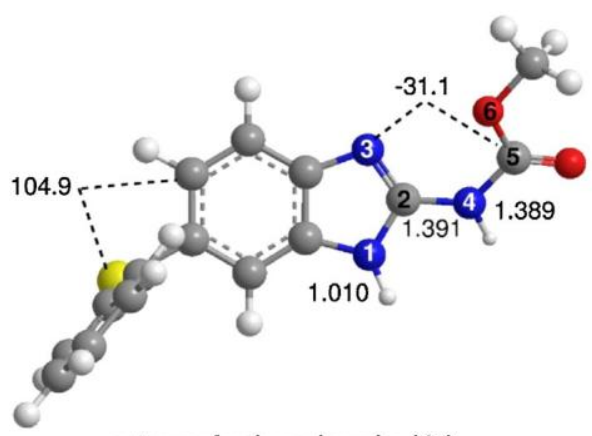

$s$-trans fenbendazole (1t)

Fig. 5. B3LYP/6-31G(d) 1c and 1t conformations of fenbendazole. The lengths are given in Angstroms, and the dihedral angles in degrees.

The energetics of radical ion pair formation through electron transfer (et) can be estimated with Eq. (1) [35]

i6. $G_{e t}=23.06\left(E_{o x}-E_{r e d}\right)-E^{*}$

where $E_{o x}$ is the oxidation potential of the donor $(\mathbf{1}), \mathrm{E}_{\text {red }}$ the reduction potential of the aromatic ketone acceptor and $E^{*}$ is the triplet energy of the ketone. Taking for $\mathbf{1} E_{\text {ox }}=1.15 \mathrm{~V}$ versus SCE, [36] and for $\mathbf{X A} E_{\text {red }}=-1.65 \mathrm{~V}$ [37] and $E_{T}=74 \mathrm{kcal} \mathrm{mol}^{-1}$ [37] an exergonic $i 6 . G_{e t}=-7.9 \mathrm{kcal} \mathrm{mol}^{-1}$ for electron transfer quenching of the $\mathbf{X A}$ triplet state can be established in acetonitrile. This is in agreement with assignment of the transient bands to the fenbendazole radical cation.

\subsection{Theoretical DFT calculations}

Geometry optimization: The ground state geometry of $\mathbf{1}$ was first analyzed. Due to the free bond rotation around the C2-N4 single bond, two rotamers $(\mathbf{1 c}$ and $\mathbf{1 t})$ are feasible, where the $\mathrm{NH}$ group and the $\mathrm{O} 6$ oxygen atom present a s-cis or a s-trans arrangement (see Fig. 5). Note that fenbendazole has several $\mathrm{C} *(X=\mathrm{C}, \mathrm{O}, \mathrm{N}$, $S)$ single bonds with free rotations; here only the more favorable rotamers (1cand $\mathbf{1 t}$ ) around the $\mathrm{C} Z \mathrm{~N} 4$ bond are presented. In these conformations the carbamate group is planar, while the phenylthio substituent is in a perpendicular arrangement relative to the benzimidazolesystem. Hence, a conformational analysiswas performed in order to characterize the most favorable structure.

According to B3LYP/6-31G(d) optimization, $1 \mathrm{t}$ is $11.7 \mathrm{kcal} \mathrm{mol}^{-1}$ higher in energy than 1c. Due to this energy gap only the latter will be considered in the singlet excitation study. Similar relative energies are obtained by single point energy calculations at the B3LYP/6-311+G(d,p) level (see Table 1).The B3LYP/6-31G(d) geometries are given in Fig. 5. Some geometrical parameters deserve special comments. In $\mathbf{1 c}$ the $\mathrm{N} 1-\mathrm{C} 2-\mathrm{N} 4-\mathrm{C} 5$ dihedral angle, $0.3^{\circ}$, points to a planar arrangement for the benzimidazole and carbamate moieties while in the $\mathbf{1 t}$ conformation, the corresponding dihedral angle is of $31.1^{\circ}$ due to the unfavorable electronic interaction between the $\mathrm{N} 1$ and $\mathrm{O} 6$ lone pairs. In addition, in the 1c conformation, the distance between the $\mathrm{H}(\mathrm{N} 1)$ hydrogen and 


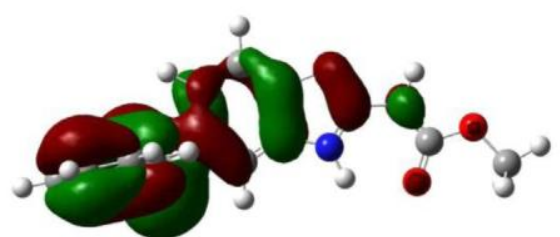

MO $78-5.46 \mathrm{eV}$

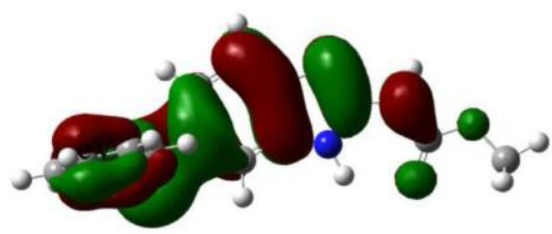

MO $77-6.02 \mathrm{eV}$

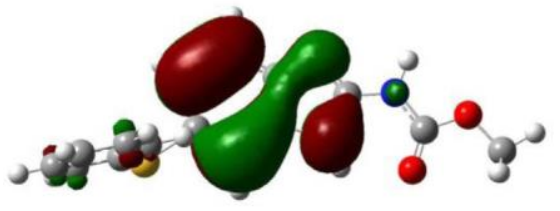

MO $76-6.33 \mathrm{eV}$

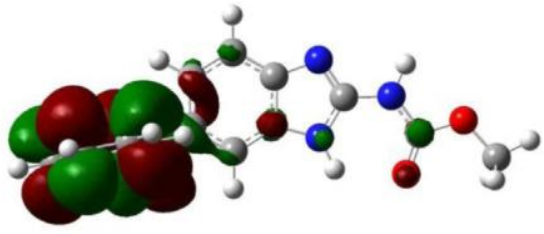

MO $810.13 \mathrm{eV}$

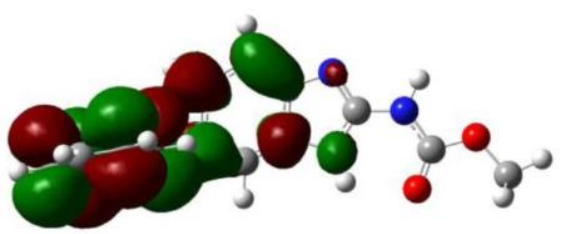

MO $80 \quad 0.06 \mathrm{eV}$

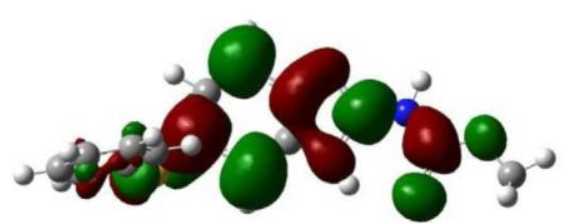

MO $79-0.69 \mathrm{eV}$

Fig. 6. B3LYP/6-31G(d) MOs involved in the key excited states of 1c.

Table 1

Total (E in a.u.) and relative energies (i6.E in $\mathrm{kcal} \mathrm{mol}^{-1}$ ) of the $\mathbf{1 c}$ and $\mathbf{1 t}$ structures.

\begin{tabular}{|c|c|c|c|c|}
\hline & \multicolumn{2}{|l|}{ B3LYP/6-31G(d) } & \multicolumn{2}{|c|}{ B3LYP/6-311+G(d,p) } \\
\hline & $E$ & $i 6 . E$ & E & $i 6 . E$ \\
\hline 1c & -1292.357308 & & -1292.626779 & \\
\hline $1 \mathrm{t}$ & -1292.338693 & 11.7 & -1292.609377 & 10.92 \\
\hline
\end{tabular}

the carboxylic O6 oxygen atom, $2.096 \AA$, points to hydrogen-bond interaction. Finally, the $\mathrm{C}-\mathrm{S}-\mathrm{C}-\mathrm{C}$ dihedral angle indicates a nearly perpendicular arrangement of the phenylthio substituent and the benzimidazole system.

Singlet and triplet excitations: The first three singlet and triplet excited states of 1c were studied at the time-dependent (TD) B3LYP/ 6-311+G(d,p)//B3LYP/6-31G(d) level. The excitation energies and oscillator strengths are given in Table 2 . In order to characterize the main molecular orbital (MO) contributor to these singlet and triplet excitations, B3LYP/6-31G(d) MOs 76-81 were analyzed, a graphical representation of these MOs is given in Fig. 6. While MOs 76, 77 and 78 correspond to HOMO-2, HOMO-1 and HOMO, the virtual MOs 79, 80 and 81 correspond to LUMO, LUMO+1 and $\mathrm{LUMO}+2$, respectively. The six MOs present a $n$ symmetry.

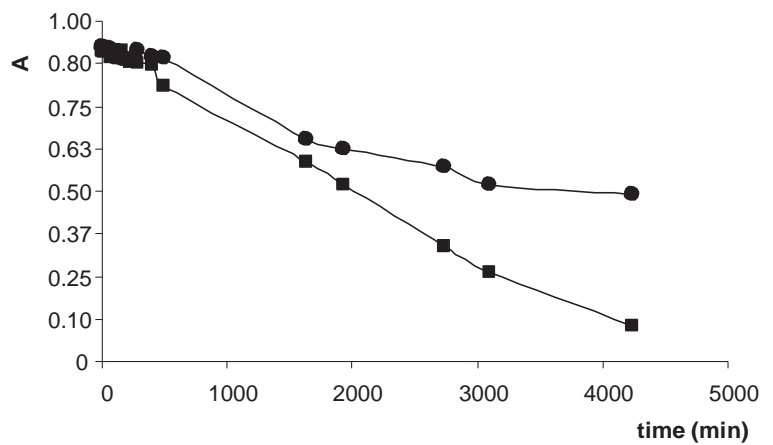

Fig. 7. Normalized absorbance changes of $\mathbf{1}$ (measured at $288 \mathrm{~nm}$ ) versus irradiation time in the absence $(\bullet)$ and in the presence of $\mathbf{X A}(\cdot)$.

The first singlet excited stateS1 presents an excitation energy of $310.69 \mathrm{~nm}(f=0.1500)$ and corresponds mainly to a $n \rightarrow n^{*}$ excitation between HOMO and LUMO. This state is located $92.0 \mathrm{kcal} \mathrm{mol}^{-1}$ above the ground state S0. The S2 singlet excited state presents an excitation energy of $276.50 \mathrm{~nm}(f=0.0041)$ and corresponds mainly to a $n \rightarrow n^{*}$ excitation between HOMO and LUMO+1. The S2 state is located $103.4 \mathrm{kcal} \mathrm{mol}^{-1}$ above the S0 ground state. Finally, the S3

Table 2

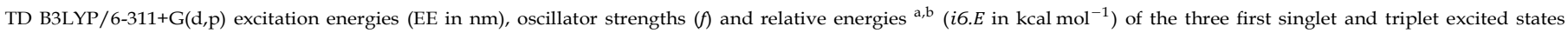
of $\mathbf{1 c}$.

\begin{tabular}{|c|c|c|c|c|c|}
\hline Excited State & Transition & & $\mathrm{EE}$ & $f$ & $i 6 . E$ \\
\hline S1 & $78 \mathrm{TI} \rightarrow 79 \mathrm{TI}^{*}$ & $(0.6758)$ & 310.69 & 0.1500 & $92.0(96.0)$ \\
\hline S2 & $78 \mathrm{TI} \rightarrow 80 \mathrm{TI}^{*}$ & $(0.6513)$ & 276.50 & 0.0041 & $103.4(105.0)$ \\
\hline S3 & $77 \mathrm{TI} \rightarrow 79 \mathrm{TI}^{*}$ & $(0.3906)$ & 266.90 & 0.2213 & 107.1 (107.5) \\
\hline \multirow[t]{2}{*}{$\mathrm{T} 1$} & $77 \mathrm{TI} \rightarrow 79 \mathrm{TI}^{*}$ & $(0.4530)$ & 369.05 & 0.0000 & $77.5(79.2)$ \\
\hline & $78 \mathrm{TI} \rightarrow 79 \mathrm{TI}^{*}$ & $(0.4759)$ & & & \\
\hline $\mathrm{T} 2$ & $78 \mathrm{TI} \rightarrow 81 \mathrm{TI}^{*}$ & $(0.5878)$ & 355.35 & 0.0000 & $80.5(81.4)$ \\
\hline T3 & $76 \mathrm{TI} \rightarrow 79 \mathrm{TI}^{*}$ & $(0.4733)$ & 321.32 & 0.0000 & $89.0(89.7)$ \\
\hline
\end{tabular}

a The TD B3LYP/6-311+G(d,p) total energy of S0 ground state of 1c is -1292.626779 (gas phase) and -1292.653195 (acetonitrile) a.u.

${ }^{\mathrm{b}}$ In parenthesis relative energies in acetonitrile. 


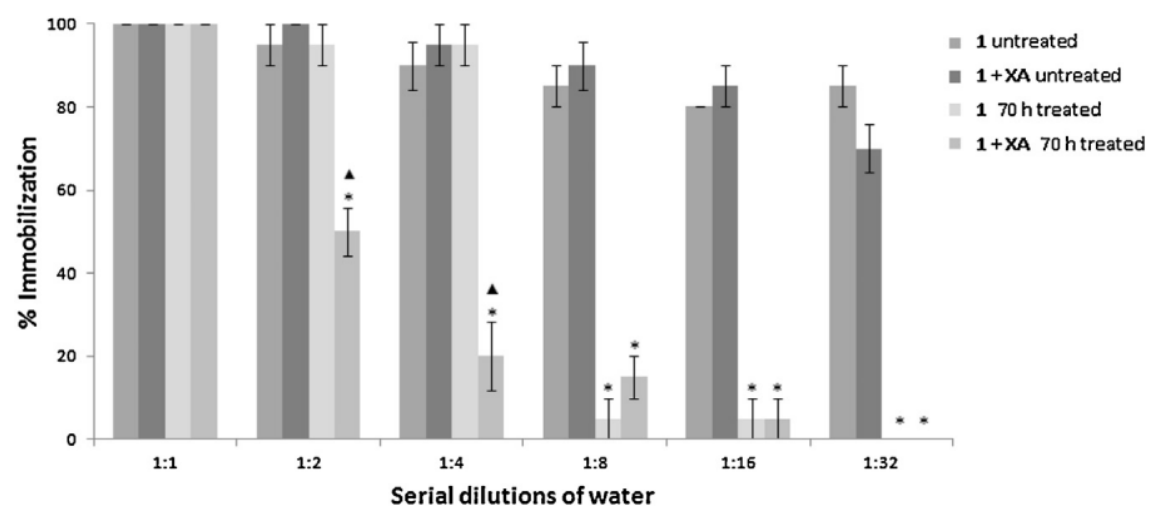

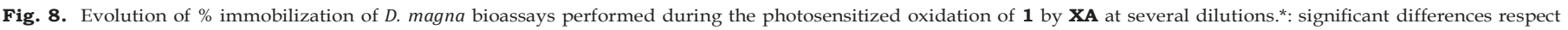
to treatment time $(p<0.05)$.

singlet excited state presents an excitation energy of $266.90 \mathrm{~nm}$ $(f=0.2213)$ and corresponds to a $n \rightarrow n^{*}$ excitation between HOMO-1 and LUMO. This state is located $107.1 \mathrm{kcal} \mathrm{mol}^{-1}$ above the $\mathrm{S} 0$ ground state.

The first T1 triplet excited state, generated by a $n \rightarrow n^{*}$ excitation between HOMO and LUMO, presents an excitation energy of $369.05 \mathrm{~nm}$ and is located $77.5 \mathrm{kcal} \mathrm{mol}^{-1}$ above the $S 0$ ground state. The T2 triplet excited state (excitation energy of $355.35 \mathrm{~nm}$ ) is associated with a $n \rightarrow n^{*}$ excitation between HOMO and LUMO+2 and is located $80.5 \mathrm{kcal} \mathrm{mol}^{-1}$ above the $\mathrm{S} 0$ ground state. The T3 triplet excited state, with excitation energy of $321.32 \mathrm{~nm}$, results from $n \rightarrow n^{*}$ excitation between HOMO- 2 and LUMO +1 and is located $89.0 \mathrm{kcal} \mathrm{mol}^{-1}$ above the $\mathrm{S} 0$ ground state.

Finally, the solvent effects of acetonitrile on the singlet and triplet excited states energies were studied using the polarizable continuum model (PCM) by TD B3LYP(PCM)/6-311+G(d,p) calculations over the gas phase B3LYP/6-31G(d) geometries. The relative energies are also given in Table 2. For the singlet states their values are 96.0 (S1), 105.0 (S2) and 107.5 (S3) kcal mol${ }^{-1}$, while the triplet states are 79.2 (T1), $81.4(\mathrm{~T} 2)$ and $89.7(\mathrm{~T}) \mathrm{kcal} \mathrm{mol}^{-1}$. Therefore, inclusion of solvent effects through a continuum model increases the gas phase energies of the excited states between 0.3 and $4.0 \mathrm{kcal} \mathrm{mol}^{-1}$.

As a summary, the theoretical calculations agree with the experimental results, providing a good estimation of the excited state energies and predicting a TITI* electronic configuration

\subsection{Photodetoxification}

Some of the BZs used as anthelmintics have a high potential for entering the environment and producing side effects on little wild animals and on aquatic microorganisms. Among them, fenbendazole is specially toxic to fresh water invertebrates such as D. magna. To check whether sunlight exposure can contribute to achieve the degradation of $\mathbf{1}$ and to minimize its impact on the environment, aerated dimethylsulfoxide solutions of $\mathbf{1}$, alone and in the presence of xanthone (XA), were photolyzed in a solar simulator. The photoreaction was monitored by HPLC, using thiabendazole as internal standard (IS). Fig. 7 shows the kinetics of disappearance of $\mathbf{1}$, which was faster in the presence of the aromatic ketone. Formation of new, well defined products was not observed.

To assess whether the observed photodegradation of $\mathbf{1}$ results in a decreased toxicity, biological assays were performed with $D$. magna as model system. The results (Fig. 8) are expressed as percentages of immobilization of daphnids exposed to serial dilutions of samples, both untreated and irradiated for $70 \mathrm{~h}$.

At 1:1 dilution all the samples exhibited a high toxicity $(100 \%$ immobilization). As shown in Fig. 8, at 1:2 and 1:4 dilutions a pronounced detoxification of the sample containing xanthone was observed. At 1:32 dilution no toxicity was detectable in the treated samples. Estimation of the concentration causing $50 \%$ immobilization (EC50) and corresponding 95\% confidence limits, calculated with Probit analysis, indicated a good fit for samples obtained after 24 h of treatment $\left(x^{2}=28.95, p=0.146\right)$. These results demonstrate that photochemical degradation results in a diminished toxicity, indicating that the photoproducts are less toxic than the parent compound 1.

\section{Conclusions}

The obtained results have proven that photodegradation of the veterinary anthelmintic fenbendazole occurs under simulated sunglight, a process that is enhanced in the presence of xanthone. The involved excited states have been characterized, both experimentally and theoretically. Photochemical treatment seems to be a potential remediation method for environmental purposes, as indicated by the observed detoxification using the established D. magna mobility assay.

\section{Acknowledgments}

Financial support from the MICINN (CTQ2010-19909) and the Generalitat Valenciana (Prometeo Program) is gratefully acknowledged.

\section{References}

[1] J. Behnke, D.J. Buttle, G. Stepek, A. Lowe, I.R. Duce, Parasites \&Vectors 1 (2008) (No pp given).

[2] M. Bossche van de, D. Thienpoint, P.G. Janssens (Eds.), Chemotherapy of Gastrointestinal Helminths in Handbook of Experimental Pharmacology, Springer, Berlin, 1985.

[3] R.K. Prichard, Parasitology 134 (2007) 1087.

[4] G.W. von Samson-Himmelstjerna, J. Blackhall, J.S. McCarthy, P.J. Skuce, Parasitology 134 (2007) 1077

[5] C. Cox, L. Wilson, M.A. Jordan, M. Yenjerla, Journal of Pharmacology and Experimental Therapeutics 328 (2009) 390.

[6] S.J. Oh, J. Park, M.J. Lee, S.Y. Park, J.-H. Lee, K. Choi, Environmental Toxicology and Chemistry 25 (2006) 2221.

[7] Pesticide EU-MRLs Database, http://ec.europa.eu/atoz_en.htm

[8] E.R. Cole, G. Crank, E. Lye, Australian Journal of Chemistry 31 (1978) 2675.

[9] G. Crank, A. Mursyldi, Australian Journal of Chemistry 35 (1982) 775.

[10] A. Kiss, D. Virag, Journal of Environmental Quality 38 (2009) 157.

[11] J.P. Escalada, A. Pajares, J. Gianotti, W.A. Massad, S. Bertolotti, F. Amat-Guerri, N.A. Garcia, Chemosphere 65 (2006) 237.

[12] V. Sarria, S. Parra, M. Invernizzi, P. Peringer, C. Pulgarin, Water Science and Technology 44 (2001) 93.

[13] H. Loewe, J. Urbanietz, R. Kirsch, D. Duewel, Ger. Offen. (1973), DE 2164690 A1 19730712.

[14] A.N. Aycock-Williams, L.K. Pham, M. Liang, H.A. Adisetiyo, L.A. Geary, M.B. Cohen, D.B. Casebolt, P. Roy-Burman, Journal of Cancer Research and Experimental Oncology 3 (2011) 115. 
[15] G. Ragno, A. Risoli, G. Ioele, M. De Luca, Chemical and Pharmaceutical Bulletin 54 (2006) 802.

[16] M.C. Jimenez, M.A. Miranda, R. Tormos, I. Vaya, Photochemical and Photobiological Sciences 3 (2004) 1038.

[17] C. Lee, W. Yang, R.G. Parr, Physical Review B 37 (1998) 785.

[18] A.D. Becke, Journal of Chemical Physics 98 (1993) 5648.

[19] W.J. Hehnre, L. Radom, P.v.R. Schleyer, J.A. Pople, Ab initio Molecular Orbital Theory, Wiley, New York, 1986.

[20] H.B. Schlegel, Journal of Computational Chemistry 3 (1982) 214.

[21] H.B. Schlegel, Geometry optimization on potential energy surface, in: D.R. Yarkony (Ed.), Modern ElectronicStructure Theory, World Scientific Publishing, Singapore, 1994.

[22] K.B. Wiberg, Tetrahedron 24 (1968) 1083.

[23] A.E. Reed, R.B. Weinstock, F.J. Weinhold, Chemical Physics 83 (1985) 735.

[24] R. Bauernschmitt, R. Ahlrichs, Chemical Physics Letters 256 (1996) 454.

[25] M.E. Casida, C. Jamorski, K.C. Casida, D.R. Salahud, Journal of Chemical Physics 108 (1998) 4439.

[26] J. Tomasi, M. Persico, Chemical Reviews 94 (1994) 2027.

[27] B.Y. Simkin, I. Sheikhet, Quantum Chemical and Statistical Theory of Solutions: A Computational Approach, Ellis Horwood, London, 1995.

[28] E. Cances, B. Mennucci, J. Tomasi, Journal of Chemical Physics 107 (1997) 3032

[29] M. Cossi, V. Barone, R. Cammi, J. Tomasi, Chemical Physics Letters 255 (1996) 327.

[30] V. Barone, M. Cossi, J. Tomasi, Journal of Computational Chemistry 19 (1998) 404.
[31] M.J. Frisch, G.W. Trucks, H.B. Schlegel, G.E. Scuseria, M.A. Robb, J.R. Cheeseman, J.A. Montgomery, T. Vreven, K.N. Kudin, J.C. Burant, J.M. Millam, S.S. Iyengar, J. Tomasi, V. Barone, B. Mennucci, M. Cossi, G. Scalmani, N. Rega, G.A. Petersson, H. Nakatsuji, M. Hada, M. Ehara, K. Toyota, R. Fukuda, J. Hasegawa, M. Ishida, T. Nakajima, Y. Honda, O. Kitao, H. Nakai, M. Klene, X. Li, J.E. Knox, H.P. Hratchian, J.B. Cross, C. Adamo, J. Jaramillo, R. Gomperts, R.E. Stratmann, O. Yazyev, A.J. Austin, R. Cammi, C. Pomelli, J.W. Ochterski, P.Y. Ayala, K. Morokuma, G.A Voth, P. Salvador, J.J. Dannenberg, V.G. Zakrzewski, S. Dapprich, A.D. Daniels, M.C. Strain, O. Farkas, D.K. Malick, A.D. Rabuck, K. Raghavachari, J.B. Foresman, J.V. Ortiz, Q. Cui, A.G. Baboul, S. Clifford, J. Cioslowski, B.B. Stefanov, G. Liu, A. Liashenko, P. Piskorz, I. Komaromi, R.L. Martin, D.J. Fox, T. Keith, M.A. Al-Laham, C.Y. Peng, A. Nanayakkara, M. Challacombe, P.M.W. Gill, B. Johnson, W. Chen, M.W. Wong, C. Gonzalez, J.A. Pople, Gaussian 03, revision C 02, Gaussian, Inc. Wallingford, CT, 2004.

[32] ISO, Water quality- determination of the inhibition of the mobility of Daphnia magna straus (Cladocera, Crustacea)- acute toxicity test, 1996, pp. 6341.

[33] H. Paul, R.D. Small, J.C. Scaiano, Journal of the American Chemical Society 100 (1978) 4520

[34] M. Goez, B.H.M. Hussein, Physical Chemistry Chemical Physics 6 (2004) 5490.

[35] D. Rehm, A. Weller, Israel Journal of Chemistry 8 (1970) 259.

[36] M. Firmino de Oliveira, N.R. Stradiotto, Journal of Pharmaceutical and Biomedical Analysis 30 (2002) 279.

[37] C. Högemann, E. Vauthey, Journal of Physical Chemistry A 102 (1998) 10051. 